Jpn. J. Phys. Fitness Sports Med. 2006, 55 Suppl. : S205 \$ 208

\title{
EFFECTS OF CARBONATED AND NONCARBONATED BEVERAGE INTAKES IN RESPONSE TO PROLONGED CYCLE ERGOMETER EXERCISE
}

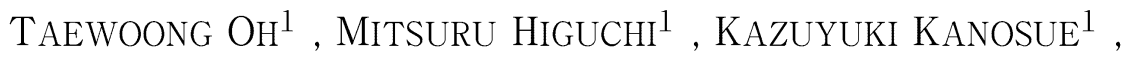 \\ ChIYOKO Usui ${ }^{2}$, ISAO MURAOKA ${ }^{1)}$, ShizUO SAKAMOTO ${ }^{1}$, \\ IKUO SHIBUICHI $^{3)}$ and HIROMICHI MiTSUDA ${ }^{3)}$
}

\begin{abstract}
Athletes have been instructed to refrain from taking carbonated beverages in the sports world, but the mechanism has not been clear. The purpose of this study was to clarify how physiological and biochemical evaluation are affected by taking a 10\% CHO carbonated beverage after cycle ergometer ( $60 \mathrm{~min}, 60 \% \dot{\mathrm{VO}}_{2} \mathrm{max}$ ). Seven subjects consumed a carbonated or noncarbonated ( $10 \%$ carbohydrate) beverage after exercise. No differences were observed in concentration of glucose, insulin, free fatty acids, $\mathrm{K}$ and $\mathrm{Na}$ in serum from carbonated beverage compared with noncarbonated beverage intakes after exercise.

These results indicate that carbonated beverage did not affect the changes of physiological and biochemical parameter after prolonged exercise, and it could be more refreshing and stimulate taste rather than noncarbonated beverage, but seemed to be hard to drink immediately after exercise because it made subjects feel as if having drunk more than they did.
\end{abstract}

(Jpn. J. Phys. Fitness Sports Med. 2006, 55 Suppl : S205 S208)

key word : body temperature, blood glucose, carbonated beverage intake, exercise

\section{Introduction}

Prolonged exercise can result in dehydration, decreasing body weight by even $1 \%$ is sufficient to impair thermoregulation and subsequent exercise performance $e^{1-3)}$. Many beverages have been formulated to replenish fluid losses during exercise as well as to potentially enhance athletic performance ${ }^{4)}$.

Carbonated beverages, are effervescent drinks that releases carbon dioxide under conditions of normal atmospheric pressure ${ }^{5)}$. Carbonation may occur naturally in spring water that has absorbed carbon dioxide at high pressures underground. It can also be a byproduct of fermentation, such as beer and some wines.

The purpose of this study was to clarify how body temperature, serum glucose level and taste are affected by taking carbonated beverage include 10\% CHO after cycle ergometer through physiological and biochemical evaluation.
Methods

\section{Subjects}

Seven healthy male college students volunteered for this crossover study approved by Waseda University ethics committee. Subject details (mean \pm standard deviation) were as follows age $22.5 \pm 0.9$ years, height $173.1 \pm 6.5 \mathrm{~cm}$, body mass $69.4 \pm 6.3$ $\mathrm{kg}$, BMI $23.1 \pm 1.4 \mathrm{~kg} / \mathrm{m}^{2}$, fat mass $17.9 \pm 4.5 \mathrm{~kg}$ and $\dot{\mathrm{VO}}_{2} \max 3.04 \pm 0.25 \mathrm{l} / \mathrm{min} / \mathrm{kg}$. The subjects had taken part in a previous ( $2 \mathrm{wk}$ prior) reliability investigation during which subjects undertook in cremental tests to exhaustion on a electromagnetically braked cycle ergometer (818 \& ERGOMEDIC, MONARK) which quantified subjects maximal oxygen consumption ( $\dot{\mathrm{VO}}_{2} \max$ ) and maximum heart rate (HRmax).

Procedure

Subjects were instructed to refrain from physical activity for $24 \mathrm{~h}$ prior to experiments and not to consume caffeine or alcohol-containing fluids the day

\footnotetext{
1) Faculty of Sport Sciences, Waseda University

${ }^{2)}$ Graduate School of Human Sciences, Waseda University

${ }^{3)}$ Beverage Research \& Development Laboratory, Asahi Soft Drinks Co., Ltd.
} 
prior to trials. Subjects were provided with a checklist to complete as they ate their provisions including a section to note any variations from the questionnaire survey provided.

Subjects were provided with a breakfast (a piece of banana, $250 \mathrm{ml}$ milk, $150 \mathrm{~g}$ steamed rice, a boiled egg ; $572 \mathrm{kcal}$ ) approximately $2 \mathrm{~h}$ prior to the commencement of the trials. The trials were conducted in environmentally stable conditions (Average room temperature : $25 \pm 1{ }^{\circ} \mathrm{C}$, humidity : $\left.50 \%\right)$.

Subjects were informed that an intensity of approximately $60 \% \dot{\mathrm{VO}}_{2}$ peak was recommended for optimal $1 \mathrm{~h}$ cycling performance. A Blood sample was taken at the completion of trial.

Beverages

After exercise subjects received $500 \mathrm{ml}$ of carbonated (about a fourfold volume of carbon dioxide com- pared to content fluid was dissolved) or noncarbonated beverage which contained $10 \%$ carbohydrate. They drank mineral waters $(200 \mathrm{ml}) 2$ hours after breakfast, and exercised for an hour after weighting.

Anthropometry Measurements

Body weight was measured with light indoor clothing without shoes to the nearest $0.1 \mathrm{~kg}$ using electronic scales (calibrated at the beginning of the study by the manufacturer). Height was measured without shoes to the nearest $0.1 \mathrm{~cm}$ on a stadiometer. Body mass index (BMI) was calculated as weight/height $2\left(\mathrm{~kg} / \mathrm{m}^{2}\right)$.

Statistics

Data are expressed as mean \pm SEM. The statistical significance $(\mathrm{p}<0.05)$ of differences was determined with a one-way analysis of variance (ANOVA) followed by a Fisher PLSD post-hoc analysis.
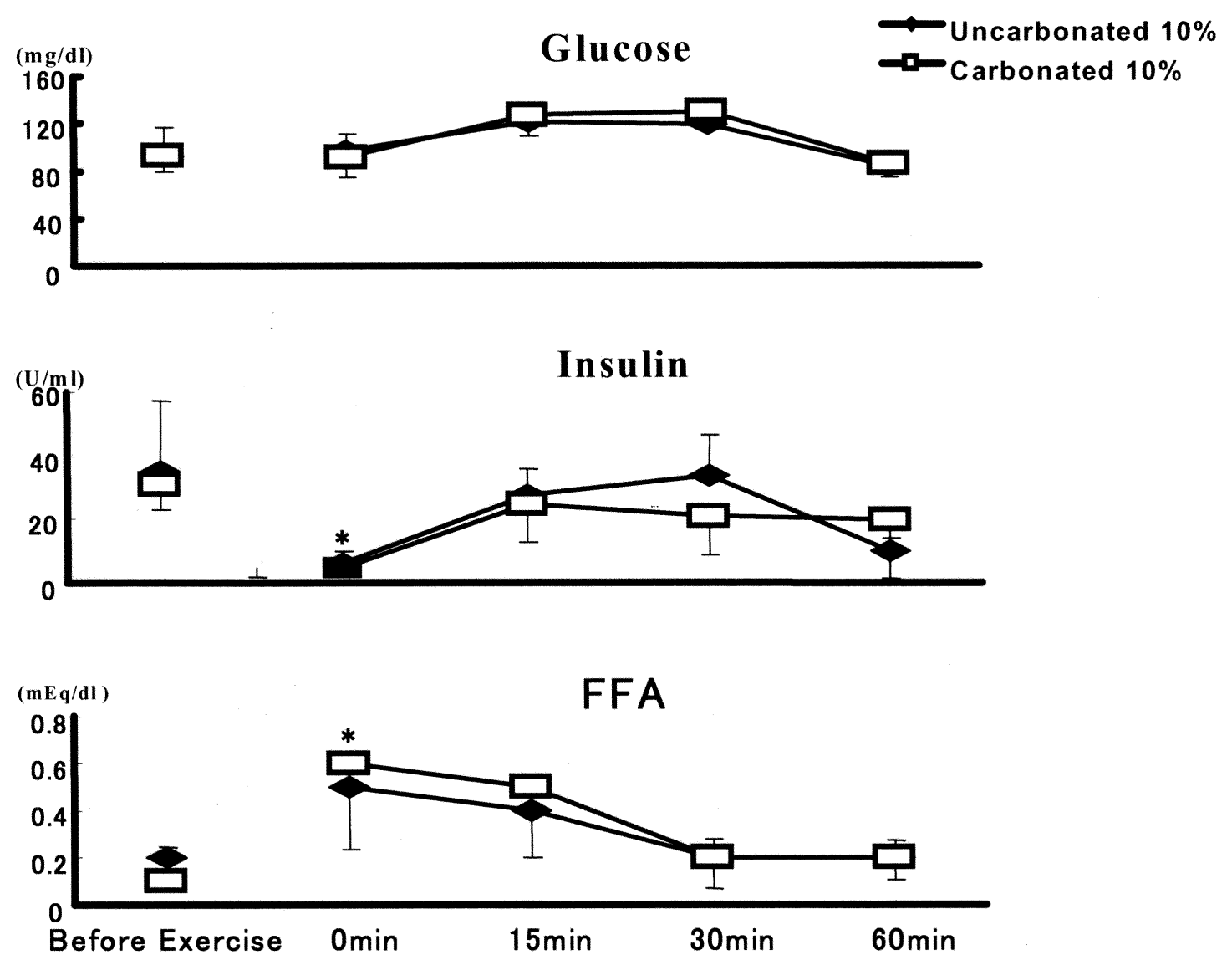

Figure 1. Serum glucose $(\mathrm{mg} / \mathrm{dl})$, insulin $(\mathrm{U} / \mathrm{ml}), \mathrm{FFA}(\mathrm{mEq} / \mathrm{dl})$ versus time $(\mathrm{min})$ during the ad libitum drinking experiments. Subjects voluntarily consumed either a $10 \%$ carbonated or noncarconated drink during 1 hour of prolonged cycle ergometer exercise $\left(60 \% \mathrm{VO}_{2}\right.$ peak $)$. Values are mean \pm SE. $*$ Significantly different from before exercise $(p<0.05)$. 


\section{Results}

Figure 1 details the effects of the carbonated beverage taken after exercise on serum glucose, insulin, FFA. There were no significant differences in the biochemical parameters during the recovery phase between drink consumption of carbonated and noncarbonated. Figure 2 details the effects of the carbonated beverage taken after exercise on serum $\mathrm{K}$ and $\mathrm{Na}$. There were no significant differences in serum $\mathrm{K}$ and $\mathrm{Na}$ concentrations between carbonated and noncarbonated consumption. Table 1 shows the mood of carbonated beverage taken after exercise by comparing with noncarbonated beverage intake. The carbonated beverage was better in terms of refreshment $(p<0.05)$ and stimulating $(p<0.01)$ taste compared to the noncarbonated beverage, but seemed to be hard to drink all at once $(\mathrm{p}<0.01)$ because it made subjects feel as if having drunk more than they did $(\mathrm{p}<0.05)$.

\section{Discussion}

The main findings of this study were that 1) intake of a carbonated beverage after prolonged exer-

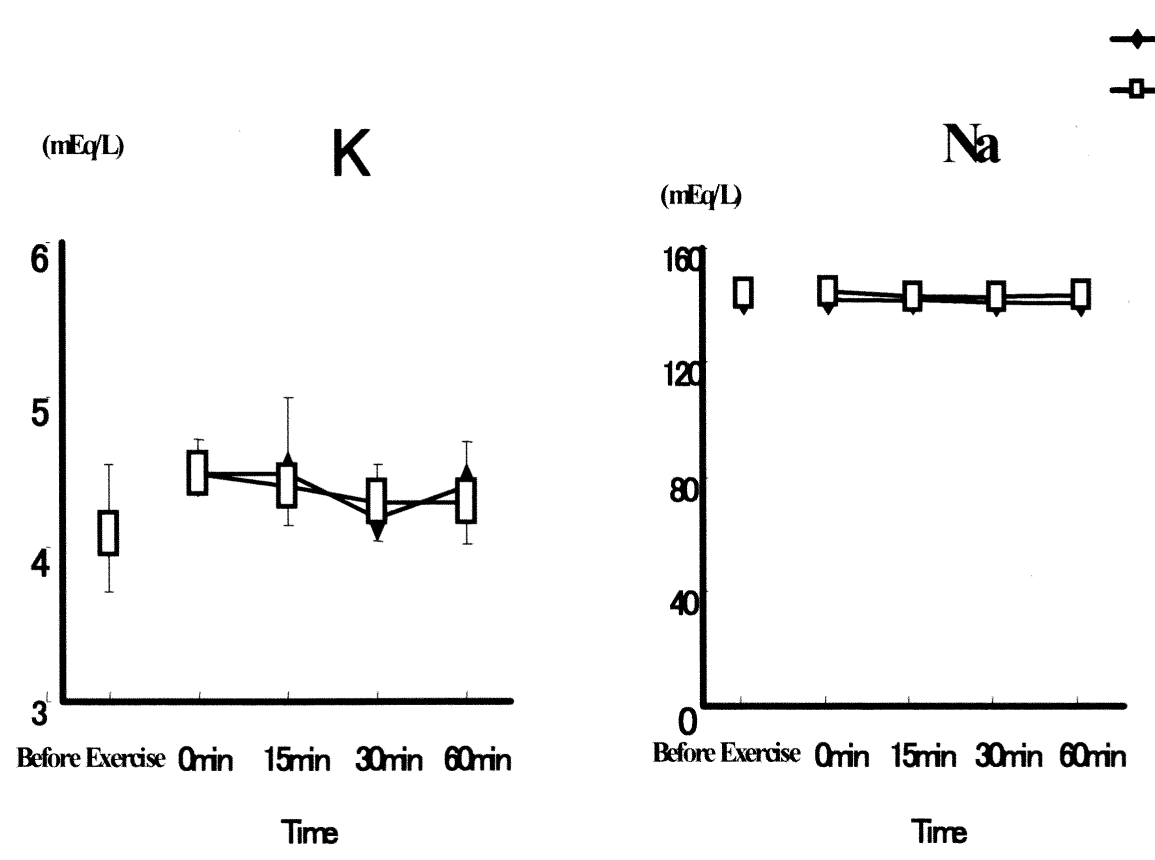

Figure 2. Serum $\mathrm{K}(\mathrm{mEq} / \mathrm{L})$ and $\mathrm{Na}(\mathrm{mEq} / \mathrm{L})$ versus time ( $\mathrm{min})$ during the ad libitum drinking experiments. Subjects voluntarily consumed either a $10 \%$ carbonated or noncarconated drink during 1 hour of prolonged cycle ergometer exercise $\left(60 \% \dot{\mathrm{VO}}_{2}\right.$ peak $)$. Values are mean $\pm \mathrm{SE}$. $*$ Significantly different from before exercise $(\mathrm{p}<0.05)$.

Table 1. Mood of carbonated beverage taken after exercise.

\section{Yes: 5 score $\leftrightarrow$ No: 1 score}

\section{Uncarbonated Carbonated t-test}

\section{Refreshment}

Subjects voluntarily consumed either a $10 \%$ carbonated or noncarconated drink after 1 hour of prolonged cycle ergometer exercise $\left(60 \% \dot{\mathrm{VO}}_{2} \max \right)$. Values are mean $\pm \mathrm{SE} .{ }^{*},{ }^{*} *$ significantly different from noncarconated drink $(\mathrm{p}<0.05, \mathrm{p}<0.01)$. 
cise did not affect the levels of serum glucose, insulin, free fatty acid, $\mathrm{K}$ and $\mathrm{Na}$ during the recovery phase compared to the noncarbonated beverage intake, 2) sensory assessment showed that the carbonated beverage was better in terms of refreshing and stimulate taste compared to the noncarbonated beverage, but seemed to be hard to drink all at once because it made subjects feel as if having drunk more than they did.

The primary goal of fluid replacement during exercise is to prevent dehydration and hyperthermia. A secondary goal is to supply an exogenous carbohydrate source for the liver and contracting skeletal muscle. Voluntary dehydration commonly occurs during exercise ${ }^{6)}$. In this study, voluntary dehydration occurred during 60 minutes of cycle ergometer exercise and resulted in substantial body fluid deficits ranging from 2.3 to $2.9 \%$ of body weight. The relative effect of two stressful conditions (hypohydration, exercise) on voluntary fluid intake has been documented ${ }^{7,8)}$. In the present study, comparison of carbonated and noncarbonated drinks did not reveal significant differences for the levels of serum glucose, insulin, free fatty acid, K, $\mathrm{Na}$ or percentage of body weight loss.

In summary, the presence of carbonation in a $10 \%$ carbohydrate drink did not influence physiological and biochemical evaluations or that the carbonated beverage was better in terms of refreshment and stimulating taste compared to the noncarbonated bever- age, but seemed to be hard to drink all at once because it made subjects feel as if having drunk more than they did after prolonged cycle ergometer exercise.

\section{References}

1) Ainslie PN, Campbell IT, Lambert JP, Maclaren DP, Reilly T. Physiological and metabolic aspects of very prolonged exercise with particular reference to hill walking. Sports Med.,(2005), 35(7), 619-47.

2) Maughan R, Shirreffs S. Exercise in the heat: challenges and opportunities. J Sports Sci.,(2004), 22(10), 917-27.

3) Wingo JE, Lafrenz AJ, Ganio MS, Edwards GL, Cureton KJ. Cardiovascular drift is related to reduced maximal oxygen uptake during heat stress. Med Sci Sports Exerc.,(2005), 37(2), 248-55.

4) White JA, Ford MA. The carbohydrate maintenance properties of an experimental sports drink. Br J Sports Med.,(1984), 18(2), 64-9.

5) Venhuis MA, Reardon EJ. Vacuum method for carbonation of cementitious wasteforms. Environ Sci Technol.,(2001), 35(20), 4120-5.

6) Maughan RJ, Merson SJ, Broad NP, Shirreffs SM. Fluid and electrolyte intake and loss in elite soccer players during training. Int J Sport Nutr Exerc Metab.,(2004), 14(3), 333-46.

7) Unnithan VB, Goulopoulou S. Nutrition for the pediatric athlete. Curr Sports Med Rep.,(2004), 3(4), 20611.

8) Maresh CM, Gabaree-Boulant CL, Armstrong LE, Judelson DA, Hoffman JR, Castellani JW, Kenefick RW, Bergeron MF, Casa DJ. Effect of hydration status on thirst, drinking, and related hormonal responses during low-intensity exercise in the heat. J Appl Physiol.,(2004), 97(1), 39-44. 